\title{
RESEARCH FOR DISTRIBUTION OF DATA FROM RISK TECHNICAL SYSTEMS
}

\author{
Nikolay Petrov ${ }^{1)}$, Galina Panayotova ${ }^{2)}$ \\ ${ }^{1)}$ Trakya University, St. Zagora, Yambol, Bulgaria, nikipetrov_1953@abv.bg \\ ${ }^{2)}$ Prof. Assen Zlatarov University, Bourgas, Bulgaria
}

\begin{abstract}
In control measurements as a result of the inevitable process of aging where the average value of the measured parameters $\bar{\Pi}_{\mathrm{j}}$ of the risk technical systems are changing uninterrupted. That is defined by the technical impossibility for their complete recovery. As a result the measured parameters $\bar{\Pi}_{\mathrm{j}}=\bar{\Pi}_{\mathrm{j}}(\mathrm{t})$ are functions of the period of technical exploitation. Because of an analogue processes in the periodical series of control measuring $\mathrm{D}=\mathrm{D}(\mathrm{t})$ and its root-mean square diversion $\sigma=\sqrt{\mathrm{D}(\mathrm{t})}$ are also functions of the period of technical exploitation.
\end{abstract}

Keywords: process of getting, technical exploitation, risk technical systems, stochastic prognostication.

\section{INTRODUCTION}

In control measurements as a result of the inevitable process of aging where the average value of the measured parameters $\bar{\Pi}_{j}$ of the risk technical systems are changing uninterrupted around a some average value $\bar{\Pi}_{j}$ in across section of the current time $\mathrm{t}$.

As a result the measured parameters $\bar{\Pi}_{\mathrm{j}}=\bar{\Pi}_{\mathrm{j}}(\mathrm{t})$ are functions of their active time for technical usage (TU). Due to analogycal processes in using measurement tools by witch are controlling relevant PTC, the disperse of relative error of each periodic series of control measurements $\mathrm{D}=\mathrm{D}(\mathrm{t})$ and its middle quadratic deviation $\sigma=\sigma(t)=\sqrt{\mathrm{D}(\mathrm{t})}$ are also functions of the current exploitation time $t$.

Because of an analogue processes in the periodical series of control measuring $D=D(t)$ and its root-mean square diversion $\sigma=\sqrt{\mathrm{D}(\mathrm{t})}$ are also functions of their active time for TU.

In this sense in the present work is proposed studying of distribution of concrete data for risky technical systems in transverse section of the current time ${ }^{t}$ for technical exploitation.

That is defined by the technical impossibility for their complete recovery.

\section{PROBLEM FORMULATION}

According to theory of errors, the low of distribution for measurement values on parameter $\Pi_{j}$ for every series periodicals controls measurements (in transverse section) stiffly is approximated from the normal law of distribution [1].

For report of time dependence $\Pi_{j}$ and $\sigma$ of current time $\mathrm{t}$, this low has aspect:

$$
y(\Pi, t)=\frac{1}{\sigma(t) \sqrt{2 \pi}} \cdot \exp \left\{-\frac{[\Pi-\bar{\Pi}(t)]^{2}}{2 \sigma^{2}(t)}\right\},
$$

where: $\mathrm{Y}(\Pi, \mathrm{t})$ is density of distribution of measurement values on parameter $\Pi(\mathrm{t}) ; \sigma=\sqrt{\mathrm{D}(\mathrm{t})}$ root-mean square diversion of the parameter $\mathrm{y}(\Pi, \mathrm{t})$.

The density of distribution $\mathrm{y}(\Pi, \mathrm{t})$ of controlled parameter $\Pi(\mathrm{t})$ with the time variable $\bar{\Pi}(\mathrm{t})$ and $\sigma(t)$ will have theoretical form as it shown in Fig.1. 


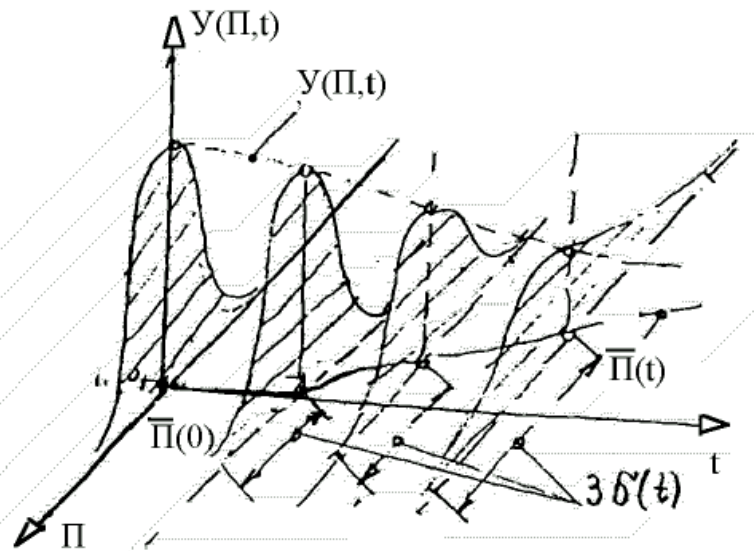

Fig. 1. Theoretical density of distribution $Y(\Pi, t)$ of measurement values on parameter $\Pi(t)$

In connection of studying of temporary (in transverse section) differencial structure of variation of nominal of parameters and confiding intervals on dispersion of nominal values for every series measurement in a process of exploitation and their prognosis in this work is offered an algorithm for decomposing of the density of distribution from equation (1), based on following interpolation correlations:

$$
\begin{gathered}
\bar{\Pi}(\mathrm{t})=\lim _{\Delta \mathrm{t}_{\mathrm{i}} \rightarrow 0}\left[\frac{\sum_{\mathrm{i}=1}^{\mathrm{n}} \Delta \mathrm{t}_{\mathrm{i}} \cdot \bar{\Pi}_{\mathrm{i}}\left(\Delta \mathrm{t}_{\mathrm{i}}\right)}{\sum_{\mathrm{i}=1}^{\mathrm{n}} \Delta \mathrm{t}_{\mathrm{i}}}\right], \\
\sigma(\mathrm{t})=\lim _{\Delta \mathrm{t}_{\mathrm{i}} \rightarrow 0}\left[\frac{\sum_{\mathrm{i}=1}^{\mathrm{n}} \Delta \mathrm{t}_{\mathrm{i}} \cdot \sigma_{\mathrm{i}}\left(\Delta \mathrm{t}_{\mathrm{i}}\right)}{\sum_{\mathrm{i}=1}^{\mathrm{n}} \Delta \mathrm{t}_{\mathrm{i}}}\right], \\
\sum_{\mathrm{i}=1}^{\mathrm{n}} \Delta \mathrm{t}_{\mathrm{i}}=\mathrm{T}_{\Sigma T \mathrm{TE}},
\end{gathered}
$$

where: $\bar{\Pi}_{\mathrm{i}}\left(\Delta \mathrm{t}_{\mathrm{i}}\right), \sigma_{\mathrm{i}}\left(\Delta \mathrm{t}_{\mathrm{i}}\right)$-nominal (average) values of parameters $\Pi(\mathrm{t})$ and his root-mean square for $i$ th series measurements;

$\mathrm{T}_{\Sigma \mathrm{TE}}-$ continuous time for $\mathrm{TU}$ in interval of observation.

In realization of decomposition (2) and (3), each of the function $\bar{\Pi}_{\mathrm{i}}\left(\Delta \mathrm{t}_{\mathrm{i}}\right), \sigma_{\mathrm{i}}\left(\Delta \mathrm{t}_{\mathrm{i}}\right)$ from formula (1) is represented through holomorphic functions of the time from polynomial type [2]:

$$
\begin{aligned}
& \bar{\Pi}(t)=a_{0}+a_{1} \cdot t+a_{2} \cdot t^{2}+\ldots+a_{r} \cdot t^{r}, \\
& \sigma(t)=b_{0}+b_{1} \cdot t+b_{2} \cdot t^{2}+\ldots+b_{s} \cdot t^{s},
\end{aligned}
$$

where: $\mathrm{a}_{0}, \mathrm{a}_{1}, \mathrm{a}_{2}, \ldots, \mathrm{a}_{\mathrm{r}}, \mathrm{b}_{0}, \mathrm{~b}_{1}, \mathrm{~b}_{2}, \ldots, \mathrm{b}_{\mathrm{s}}$-are constant coefficients determined by systems algebraic equations respective regarding to $\bar{\Pi}(\mathrm{t}), \sigma(\mathrm{t})$ in a priory known statistical coordinates $\Pi_{\mathrm{K}}, \mathrm{t}_{\mathrm{K}}(\mathrm{k}=1,2, \ldots, \mathrm{r}), \sigma_{\mathrm{m}}, \mathrm{t}_{\mathrm{m}}(\mathrm{m}=1,2, \ldots, \mathrm{s})$. The ranks of the polynomials (5) are determined by the conditions:

$$
\begin{aligned}
& a_{r+1} \cdot t^{r+1} \leq 10^{-2} \cdot\left[\bar{\Pi}(t)-a_{r+1} \cdot t^{r+1}\right], \\
& b_{s+1} \cdot t^{s+1} \leq 10^{-2} \cdot\left[\sigma(t)-b_{s-1} \cdot t^{s+1}\right],
\end{aligned}
$$

ensuring insignificance from second order respective to $(\mathrm{r}+1),(\mathrm{s}+1)$ members. Substituting the functions $\bar{\Pi}(\mathrm{t}), \sigma(\mathrm{t})$ from equations (5) in equation (1), we obtain nontrivial parametric distribution, depended from the time of technical exploitation. In [4] this distribution is studied for elementary case $\bar{\Pi}(\mathrm{t})=\mathrm{a}_{0}+\mathrm{a}_{1} \cdot \mathrm{t}$.

Let we do an investigation of this distribution with $\bar{\Pi}(\mathrm{t})$ having more complex general form (5) and arbitrary approximating function for $\sigma(\mathrm{t})$. At these conditions an equation (1) is transformed in the form:

In the presented article is done an investigation of this distribution with $\bar{\Pi}(\mathrm{t})$ which have more complex general presentation (5) and arbitrary approcsimation function for $\sigma(\mathrm{t})$. However is obtained inequality from the type:

$$
\mathrm{y}(\Pi, \mathrm{t})=\frac{1}{\sigma(\mathrm{t}) \sqrt{2 \pi}} \cdot \exp \left\{-\frac{\Pi^{2}-2 \Pi \bar{\Pi}(\mathrm{t})+(\bar{\Pi}(\mathrm{t}))^{2}}{2 \sigma^{2}(\mathrm{t})}\right\},
$$

We are logarithmating an equation (7) and doing respective mathematical transformations from which is obtained:

$$
\begin{aligned}
& \ln \mathrm{Y}(\Pi, \mathrm{t})=\ln \frac{1}{\sigma(\mathrm{t}) \sqrt{2 \pi}}+\ln \exp \left\{-\frac{\Pi^{2}-2 \Pi \bar{\Pi}(\mathrm{t})+(\bar{\Pi}(\mathrm{t}))^{2}}{2 \sigma^{2}(\mathrm{t})}\right\}= \\
& =-\ln \sigma(t)-0,5 \cdot \ln 2 \pi-0,5 \cdot(\sigma(t))^{-2} \cdot\left[\Pi^{2}-2 \Pi \bar{\Pi}(t)+(\bar{\Pi}(t))^{2}\right]= \\
& =-\ln \sigma(t)-0,5 \cdot \ln 2 \pi-0,5 \cdot(\sigma(t))^{-2} \cdot\left[\begin{array}{l}
\Pi^{2}-2 \Pi\left(a_{0}+a_{1} t+\ldots+a_{r} t^{r}\right)+ \\
+\left(a_{0}+a_{1} t+\ldots+a_{r} t^{r}\right)^{2}
\end{array}\right]= \\
& =-\ln \sigma(t)-0,5 \cdot \ln 2 \pi-0,5 \cdot(\sigma(t))^{-2} \cdot\left[\begin{array}{l}
\sum_{k=0}^{r}\left(\Pi-a_{k} k^{k}\right)^{2}+2 \sum_{i=0}^{r-1} \sum_{k=i+1}^{r} a_{i} a_{k} k^{i+k}- \\
-(r-1) \Pi^{2}
\end{array}\right] \text {, }
\end{aligned}
$$

We are doing an anti logaritmation of an above mathematical expression and after a respective mathematical transformations is obtained: 


$$
\begin{aligned}
& \mathrm{y}(\Pi, \mathrm{t})=\frac{1}{\sigma(\mathrm{t}) \sqrt{2 \pi}} \cdot \exp \left\{-\frac{1}{2 \sigma^{2}} \sum_{\mathrm{k}=0}^{\mathrm{r}}\left(\Pi-\mathrm{a}_{\mathrm{k}} \mathrm{t}_{\mathrm{k}}\right)^{2}\right\} . \\
& \cdot \exp \left\{-\frac{1}{\sigma^{2}} \sum_{\mathrm{i}=0}^{\mathrm{r}-1} \sum_{\mathrm{k}=\mathrm{i}+1}^{\mathrm{r}} \mathrm{a}_{\mathrm{i}} \mathrm{a}_{\mathrm{k}} \mathrm{t}^{\mathrm{i}+\mathrm{k}}\right\} \cdot \exp \left\{\frac{(\mathrm{r}-1)}{2 \sigma^{2}} \Pi^{2}\right\} .
\end{aligned}
$$
mode:

An equation (8) cam be presented in general

$$
\begin{gathered}
\mathrm{y}(\Pi, \mathrm{t})=\frac{1}{\sigma(\mathrm{t}) \sqrt{2 \pi}} \cdot \prod_{\mathrm{k}=0}^{\mathrm{r}} \exp \left\{-\frac{\left(\Pi-\mathrm{a}_{\mathrm{k}} \mathrm{t}^{\mathrm{k}}\right)^{2}}{2 \sigma^{2}}\right\} . \\
\cdot \prod_{\mathrm{i}=0}^{\mathrm{r}-1} \prod_{\mathrm{k}=\mathrm{i}+1}^{\mathrm{r}} \exp \left\{-\frac{\mathrm{a}_{\mathrm{i}} \mathrm{a}_{\mathrm{k}} \mathrm{t}^{\mathrm{i}+\mathrm{k}}}{2 \sigma^{2}}\right\} \cdot \exp \left\{\frac{(\mathrm{r}-1)}{2 \sigma^{2}} \Pi^{2}\right\} .
\end{gathered}
$$

Equation (9) represents nontrivial parametrical distribution, appearing in transverse section time function for technical exploitation of relevant risky technical system. The dispersing of it's values in the confidential interval with probability, higher or equal to $0,9973 \mathrm{e} \pm 3 \sigma(\mathrm{t})$.

For doing of investigation of equation (9) for distribution law, it is presented in the form:

$$
\begin{gathered}
\mathrm{y}(\Pi, \mathrm{t})=\frac{1}{\sigma\left(\mathrm{t}_{\mathrm{m}}+\mathrm{T}_{\Pi}\right) \sqrt{2 \pi}} \cdot \prod_{\mathrm{k}=0}^{\gamma} \exp \left\{-\frac{\left(\Pi-\mathrm{a}_{\mathrm{k}}\left(\mathrm{t}_{\mathrm{m}}+\mathrm{T}_{\Pi}\right)^{\mathrm{k}}\right)^{2}}{2 \sigma^{2}}\right\} \cdot \\
. \prod_{j=0}^{\gamma-1} \prod_{\mathrm{k}=i+1}^{\gamma} \exp \left\{-\frac{\mathrm{a}_{\mathrm{i}} \mathrm{a}_{\mathrm{k}}\left(\mathrm{t}_{\mathrm{m}}+\mathrm{T}_{\Pi}\right)^{i+k}}{2 \sigma^{2}}\right\} \cdot \exp \left\{\frac{(\mathrm{r}-1)}{2 \sigma^{2}} \Pi^{2}\right\} .
\end{gathered}
$$

The investigation of (10) is accomplished by the program Mathematica, in which is obtained the distribution in transverse section of parameter $\mathrm{y}(\Pi, \mathrm{t})$. For concrete investigating risky technical system is shown the presented example.

\section{EXAMPLE FOR INVESTIGATING A DISTRIBUTION OF POWER OF THE TRANSMITTER OF AVIATION COMMUNICATION INFORMATION SYSTEM P-862}

Technical exploitation of aviation communication information system P-862 has begun in 1995 year. It was assembled on flying apparatus Mig-29, № 01 . The variation of the sensibility of a receiver and the power of the transmitter is shown on fig. 2 and fig.3 [3]. They are processed with a statistical software "Mathematica". By tacticstechnical data the examining system P-862 has frequency range $(100,000-149,975) \mathrm{MHz}$ and from $(220,000-399,975) \quad \mathrm{MHz}$. The sensibility of a receiver is not worse by $3 \mu \mathrm{V}$. The power of a transmitter is not worse by $25 \mathrm{~W}$. An investigation of serial number 20 corresponds to the beginning of 2002 year. An investigation of serial number 30 corresponds to the beginning of 2003 year. An investigation of serial number 40 corresponds to the beginning of 2005 year. The sequential number of measurement from figures 2 and 3 correspond to the current total amount of usage of P-862 and are put on the $\mathrm{x}$-axis. The comparison between those real deviations of the parameters and the theoretical values from (10) is close to $5 \%$. This is an indication that (10) is can be used as a model for a parametric regression with sufficient accuracy.

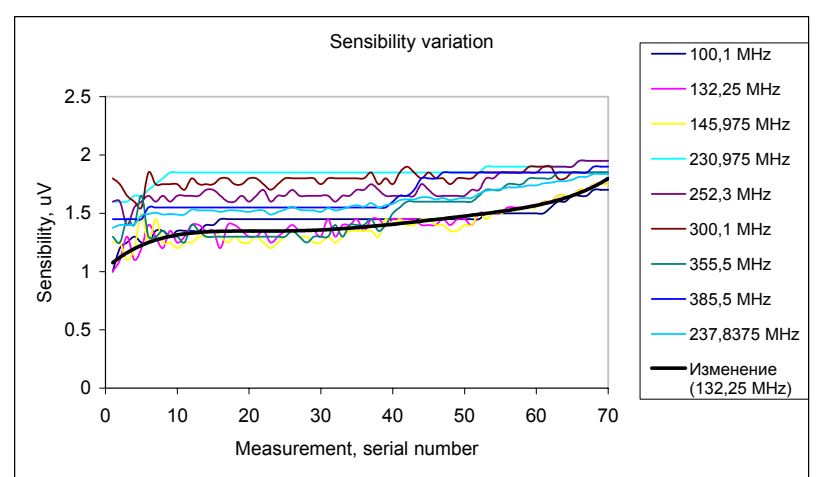

Fig. 2. Variation of the sensibility of P-862 for measurements leading in 3 years period $(2003$ - 2005)

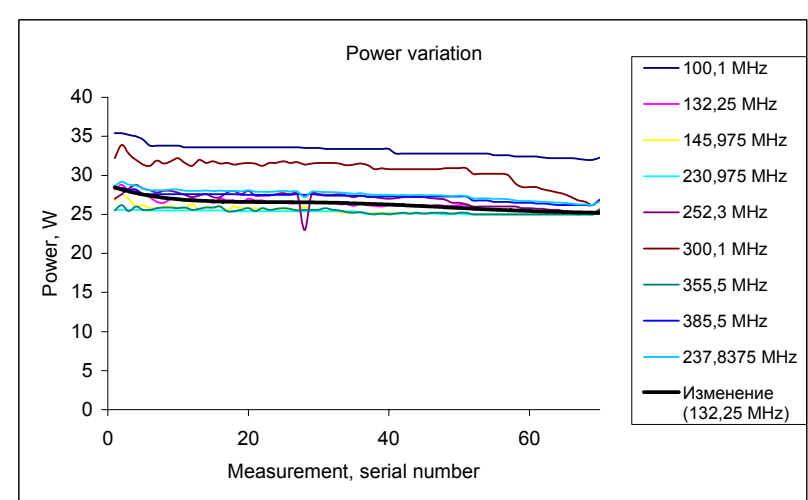

Fig. 3. Variation of the power of transmitting station

$P-862$ at measurements leading in 3 years period (2003-2005)

\section{CONCLUSION}

As a result of the making in this paper investigations could be formulated the following conclusions:

1. There is obtained nontrivial parametrical law of distribution of parameters of technical system with rendering of account evolutions of nominal values and their average quadratic deviations.

2. There is studying a real exploitation distribution of capacity of transmitter of communication information system P-862 assembling of flying machine type Mig-29. 


\section{REFERENCES}

[1] N. Petrov. Use Reliability of Risk Technical Systems. Publishing house "Uchkov", Jambol, ISBN954-9978-26-5, 2002. (in Bulgarian)

[2] Technical description of communication information system P-862. IVT, Sofia, 1995. (in Bulgarian)

[3] N. Petrov, G. Panayotova, M. Diulgerova. Nontrivial laws of distribution, using for stochastic processing of data of flying machines. Annual of University "Prof.Asen Zlatarov", Bourgas, 2003. (in Bulgarian)

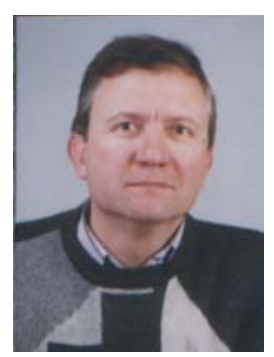

Nikolay Ivanov Petrov received M.Sc. degree from Georgi Benkovski Higher Military Institution of Air Forces, Dolna Mitropolia, Bulgaria - Specialty Communicative equipment of aircrafts. He got Ph.D. degree with doctorate thesis Optimizing and control of technical usage of military air systems and Dr. Science degree in Automated Systems for Information Technology and Management from Military Academy - Institute for Perspective Defense Research, Sofia.
Since 2001, he has been working as an Assistant Professor and Assoc. Professor at University Assen Zlatarov - Burgas, Bulgaria and Trakian University Stara Zagora, Yambol, Bulgaria. In 2007 he was awarded Professor by specialty, Atomized Systems for Treatment of Information and Control. He has more than 250 scientific works, publications and developments, 50 of which - abroad. He has published 15 scientific books and textbooks, 5 of which - monographs.

His research activities are centered on Automated Systems, Risk Technical Systems and Electronic devices for measuring.

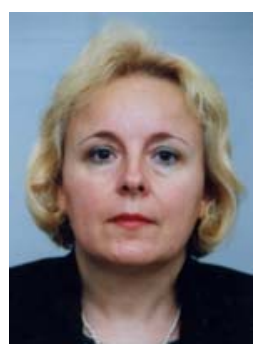

Galina Panayotova is a Doctor of Mathematics and Assoc. Prof. at the Department of Mathematics at University "Prof. Dr. As. Zlatarov", Burgas and Burgas Free University.

She works in the field of applications of quasi-linear hyperbolic systems of partial differential equations who characterized a variety of physical problems and investigation of risk technical systems.

She is the author of more 80 scientific publications, books and textbooks. 